\title{
O TERCEIRO HOMEM NO "PARMÊNIDES" DE PLATÃO: A ESTRUTURA DO ARGUMENTO E UMA PROPOSTA DE SOLUÇÃO
}

\section{THE THIRD MAN IN PLATO'S “PARMENIDES": ARGUMENT STRUCTURE AND ASOLUTION PROPOSAL}

Guilherme da Costa Assunção Cecílio* gcacecilio@hotmail.com

RESUMO O argumento do Terceiro Homem presente no "Parmênides" constitui uma formidável objeção à teoria das Ideias, à qual Platão não apresentou resposta explícita. A despeito disso, cremos ser possivel haurir da filosofia platônica uma solução para a referida objeção, solução esta que estaria verossimilmente à disposição do filósofo. Sendo assim, compreende-se que Platão não tenha sido forçado a renunciar à teoria das Ideias, ao menos no que se refere às dificuldades que o Terceiro Homem lhe opõe.

Palavras chave: Teoria das Ideias, "Parmênides", argumento do Terceiro Homem, autopredicação, não-identidade.

Abstract: The Third Man Argument presented in the "Parmenides" is a formidable objection to the Theory of Forms, one which Plato did not provide an explicit answer to. In spite of that we believe it is possible to draw from Plato's philosophy a solution to the referred objection, and one which likely would be available to the philosopher. Thus, it becomes clear that Plato was not forced to renounce his Theory of Forms, at least with regard to the difficulties that the Third Man Argument raises to it.

1 IFRJ e PPGF-UFRJ. Artigo recebido em 18/12/2015 e aprovado em 05/05/2016. 
Keywords: Theory of Forms, "Parmenides", the Third Man Argument, selfpredication, non-identity.

\section{Introdução}

O argumento do Terceiro Homem é a mais célebre objeção à teoria das Ideias ${ }^{1}$. Sua história remonta ao próprio "Parmênides" de Platão², bem como à "Metafísica" aristotélica ${ }^{3}$, percorrendo um longo caminho até os dias atuais. $\mathrm{Na}$ história mais recente dos estudos platônicos, houve um aumento de interesse tão notável por ele que Kenneth Sayre (2005, pp. 276, nota 23) exprimiu a seguinte queixa: "No commentator [...] should be content with the disproportionate attention given the 'third man' argument in recent literature" 4 . Um novo trabalho sobre o Terceiro Homem exige, desde o princípio, ao menos uma justificativa.

O fascínio que o "Parmênides", em geral, e esse argumento, em particular, exercem sobre a crítica hodierna pode ser, em parte, explicado pela desconfiança, tão própria de nossos dias, sobre qualquer teoria metafísica. Sem dúvida seria possível fazer, do nosso ponto de vista, várias críticas à chamada teoria das Ideias5; contudo, no "Parmênides", o próprio Platão, ao que parece, demonstra estar consciente das aporias enraizadas no seio de sua teoria ontológica, uma vez que contra ela apresenta várias objeções, dentre as quais se destaca o argumento do Terceiro Homem.

A despeito do caráter crítico do "Parmênides", o diálogo tem servido de marco decisivo para o estabelecimento do quadro geral da filosofia platônica. A ele se reportam os que pretendem conferir uma nova face ao pensamento do ateniense, como os comentadores que, com diversas nuanças, supõem o abandono da teoria das Ideias por parte de Platão; e também a ele têm de remeter os que sustentam a tese contrária.

\footnotetext{
Prm. 131e-132b e 132d-133a.

Metaph. 990b15-17.

Para uma breve análise da recepção contemporânea do Terceiro Homem no "Parmênides", cf. CECÍLIO (2016).

4 Sabe-se que a expressão ‘teoria das Ideias' é puramente didática, não encontrando paralelo nos textos de Platão. Servimo-nos livremente dela neste trabalho por julgar que, feitas certas ressalvas, ela é inofensiva e também útil. É evidente que ao falarmos de 'teoria das Ideias' não pretendemos atribuir a Platão um tratamento perfeitamente sistemático da questão das Ideias: o termo ‘teoria' certamente não está sendo usado no mesmo sentido que em 'teoria da relatividade', por exemplo. Contudo, é inegável que se encontram, espalhadas pelos escritos de Platão, recorrentes afirmações de que existem certos entes inteligíveis; é, pois, conveniente chamar de 'teoria' o conjunto destas afirmações sobre as Ideias, ou, se se preferir, é possível fazer-lhe referência com as expressões 'doutrina' ou 'hipótese das Ideias'.

5 Todas as traduções de trechos do "Parmênides" utilizadas neste trabalho referem-se a esta edição: PLATÃO. "Parmênides”. Tradução e notas de Maura Iglésias e Fernando Rodrigues. São Paulo: Loyola, 2003. Por vezes, no entanto, permitimo-nos fazer sutis alterações na tradução dos referidos autores, como neste caso.
} 
Em semelhante controvérsia, o argumento do Terceiro Homem frequentemente ocupa posição de destaque. Ele constitui, de fato, uma formidável objeção à ontologia platônica. Se essa objeção mostra-se inescapável, existe uma forte razão para supor que o filósofo não se tenha obstinadamente aferrado a uma teoria indefensável. Por outro lado, se ela se revelar uma objeção superável é, então, provável que Platão não tenha sido forçado a abdicar daquilo que parece ser o fulcro de sua filosofia, a teoria das Ideias. Sendo assim, determinar a gravidade dessa objeção é, de alguma forma, lidar com a ontologia do filósofo e, eventualmente, ser capaz de apreciar sua consistência.

Em suma, cremos ser justificado tratar, uma vez mais, do Terceiro Homem porque, por um lado, trata-se de um argumento extremamente conciso e, ao mesmo tempo, poderoso, dele dependendo, de algum modo, a validade da teoria das Ideias. Por outro lado, parece-nos que ainda não se trata de uma questão resolvida.

\section{Reconstrução do argumento do Terceiro Homem}

Antes de avaliarmos o peso da objeção do Terceiro Homem para a filosofia de Platão, é indispensável compreendê-la adequadamente. Leiamos, pois, em primeiro lugar, o trecho relevante do diálogo.

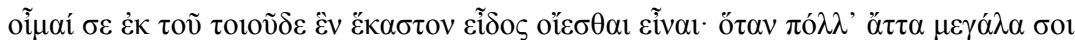

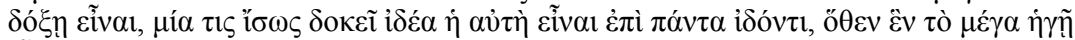
عĩval.

$\dot{\alpha} \lambda \eta \theta \tilde{\eta} \lambda \varepsilon_{\varepsilon} \varepsilon 1 \varsigma, \varphi \alpha ́ v \alpha 1$.

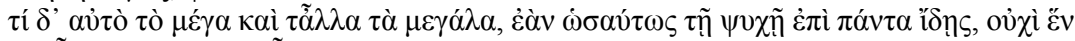

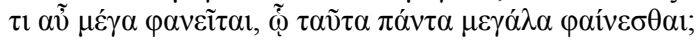

हैоเкعV.

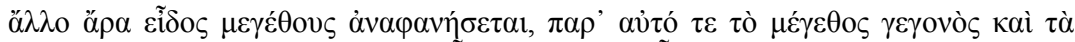

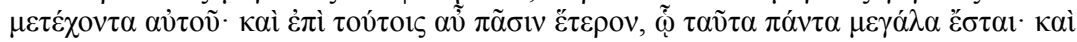

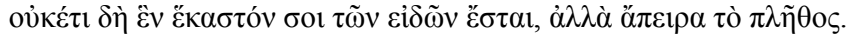

Creio que tu crês que cada forma é uma [ह̂े ] pelo seguinte: quando algumas coisas, múltiplas, te parecem ser grandes, talvez te pareça, a ti que as olhas todas, haver uma única $[\mu i ́ \alpha]$ e mesma ideia em todas; donde acreditas o grande ser um [Ēv].

Dizes a verdade, disse ele.

Mas... e quanto ao grande mesmo e às outras coisas grandes? Se olhares da mesma maneira, com a alma, para todos esses, não aparecerá, de novo, um grande, um [ع̈v], em virtude do qual é necessário todas aquelas coisas aparecerem como grandes?

Parece que sim.

Logo, uma outra forma de grandeza aparecerá, surgindo ao lado da grandeza mesma e das coisas que desta participam. E, sobre todas essas, aparecerá de novo outra, de modo a, em virtude dela, todas essas serem grandes. E não mais será uma [Ēv] cada uma das tuas formas, mas ilimitadas em quantidade. (Prm. 132a-b) ${ }^{6}$. 
Para evidenciar a estrutura lógica do trecho supracitado, valemo-nos do importante estudo de Gregory Vlastos7, mas também de contribuições de outros estudiosos. Eis o esquema que propomos:

(i) O dado de base é uma multiplicidade (indivíduos a, b, c, etc.) que possui determinada propriedade $\mathrm{F}$.

(ii) "um de muitos" 8: A essa multiplicidade corresponde uma unidade, a Ideia F-dade, em virtude da qual a multiplicidade possui a propriedade F.

(iii) autopredicação: F-dade é F.

(iv) não-identidade: Se x possui a propriedade $F$, x não coincide com $\Phi$, a Forma em virtude da qual x possui $F$.

De acordo com (iii), a própria Ideia F-dade é F; logo, ela pode ser o substituto da variável x em (iv), o que impõe a existência de uma nova Forma, Fdade1, que sirva como substituto da variável $\Phi$. Como F-dade1 está sujeita à autopredicação, F-dade1 também pode substituir a variável x na premissa (iv), instaurando-se assim o regresso infinito das Formas.

Convém agora cotejarmos a nossa reconstrução do argumento com o texto do "Parmênides".

Os passos (i) e (ii) encontram correspondência nesta afirmação:

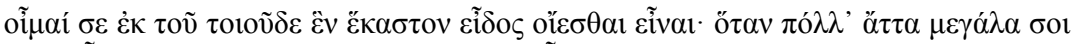

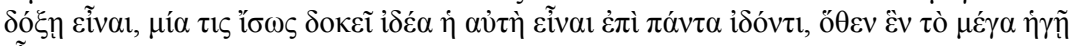
عĩvol.

Creio que tu crês que cada forma é uma [ềv] pelo seguinte: quando algumas coisas, múltiplas, te parecem ser grandes, talvez te pareça, a ti que as olhas todas, haver uma única [ $\mu i ́ \alpha]$ e mesma ideia em todas; donde acreditas o grande ser um [غ̌v]. (Prm. 132a).

Nela está contida o dado de base, isto é, a existência de várias coisas sensíveis que são grandes, ou seja, uma multiplicidade empírica de indivíduos dotados da propriedade F. Tal multiplicidade se explica por referência a "haver uma única $[\mu i ́ \alpha]$ e mesma ideia em todas", a Ideia de Grandeza ou, em geral, F-dade: trata-se aqui do princípio do "um de muitos".

Quanto à autopredicação, cremos que ela opere no seguinte trecho:

349. Neste importante artigo, Vlastos defendeu a tese radical de que a objeção do Terceiro Homem redundaria numa contradição stricto sensu entre duas das premissas do argumento, posição que ele mais tarde veio a retificar neste outro importante artigo sobre o tema: VLASTOS, G. "Plato's 'Third Man' Argument (Parm. 132A1-B2): Text and Logic". The Philosophical Quarterly, v. 19, n. 77, 1969. pp. 289-301. Para uma análise detalhada desses trabalhos de Vlastos, cf. CECílIO (2015).

7 Este princípio é explorado por comentadores de língua inglesa sob o nome 'One over Many', frequentemente abreviado 'OM'. Cf. Strang (1963); Cohen (1971). O princípio do "um de muitos" nada mais é do que uma reformulação da premissa A1 do artigo de Vlastos (1954, pp. 320): "(A1) If a number of things, a, b, c, are all F, there must be a single Form, F-ness, in virtue of which we apprehend a, b, c, as all F". 


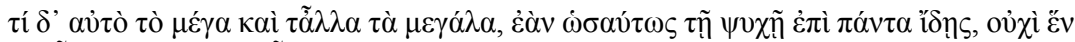

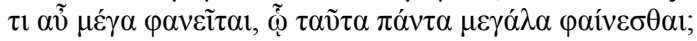

Mas... e quanto ao grande mesmo e às outras coisas grandes? Se olhares da mesma maneira, com a alma, para todos esses, não aparecerá, de novo, um grande, um [Ëv], em virtude do qual é necessário todas aquelas coisas aparecerem como grandes? (Prm. 132a).

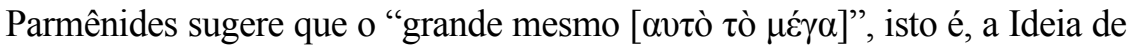

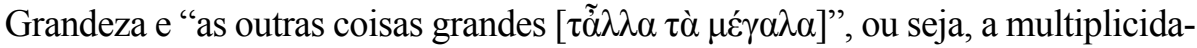
de sensível de que se partiu, sejam consideradas "da mesma maneira", expressão que traduz o advérbio grego $\hat{\omega} \sigma \alpha v ́ \tau \omega \varsigma:$ aqui parece residir um sinal da autopredicação9. Segundo o que foi há pouco admitido, as coisas sensíveis são grandes;

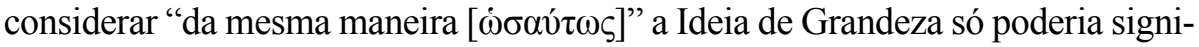
ficar, então, predicar também dela o "grande", ou seja, a autopredicação.

A autopredicação é ainda mais visível na conclusão do argumento:

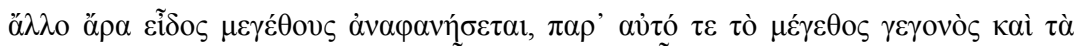

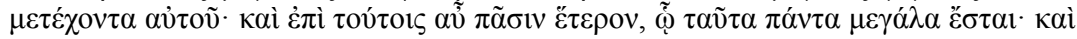

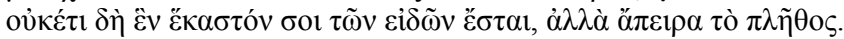

Logo, uma outra forma de grandeza aparecerá, surgindo ao lado da grandeza mesma e das coisas que desta participam. E, sobre todas essas, aparecerá de novo outra, de modo a, em virtude dela, todas essas serem grandes. E não mais será uma [Ẽv] cada uma das tuas formas, mas ilimitadas em quantidade. (Prm. 132a-b).

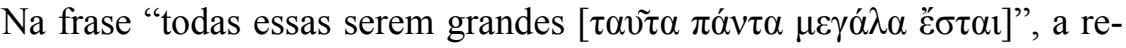
ferência de "todas" patentemente inclui a Ideia de Grandeza de que se partiu, bem como outras Ideias de Grandeza derivadas do regressus, isto é, afirma-se que as Ideias de Grandeza são grandes.

Já o princípio de não-identidade está apenas implícito em todo o trecho, mas nem por isso ele é menos operante. Bem ao contrário, sobre ele está fundada toda a argumentação: a suposição inicial de que existe uma Ideia para dar conta de uma multiplicidade que possui a propriedade $\mathrm{F}$ está baseada na convicção de que a posse dessa propriedade se explica por referência a um indivíduo, por assim dizer, externo ao grupo de indivíduos caracterizados por F; e quando a própria Ideia passa a ser caracterizada por F (autopredicação), a mesma convicção impõe a existência de uma nova Ideia.

Sendo assim, estamos em condições de concluir que o Argumento do Terceiro Homem, tal como ele está redigido no "Parmênides", contém os princí-

9 Ativemo-nos à "primeira versão" do Terceiro Homem presente no "Parmênides"; julgamo-nos dispensados de fazer a mesma análise da "segunda versão" - contida em Parmênides 132c-133a - porque, tal como Vlastos, acreditamos que ambas as "versões" contêm as mesmas etapas lógicas. 
pios que acabamos de expor ${ }^{10}$. Convém salientar que ao afirmá-lo não estamos nos comprometendo com a tese de que princípios, exatamente como eles operam no "Parmênides", sejam também princípios gerais da teoria das Ideias. De fato, se assim o fosse, a doutrina das Ideias estaria inelutavelmente impugnada pela dificuldade do regresso infinito. Bem ao contrário, acreditamos que o argumento não constitui uma fatal objeção a esta teoria.

Antes de avançarmos, convém prestarmos alguns esclarecimentos gerais sobre o Terceiro Homem e dos princípios que o constituem.

\subsection{Observações terminológicas}

O famoso princípio da autopredicação é também chamado por alguns de princípio da autoexemplificação ${ }^{11}$. Isso reflete a tentativa, em si mesma correta, de evitar o sabor linguístico da expressão 'autopredicação'. De fato, predicação é algo que, a princípio, diz respeito somente à linguagem; mas as Ideias não são entes linguísticos, não são predicados que se predicam de si mesmos ${ }^{12}$. Ao contrário, $\mathrm{o}$ termo 'autoexemplificação' indicaria que se trata de um ente que se autoexemplifica, isto é, manifesta a propriedade a si associada: a Beleza exemplifica o belo, etc.

Embora concordemos com tal observação, a autopredicação já é uma expressão consolidada, de modo que preferimos mantê-la, para não acrescentar mais um elemento complicador à discussão.

Analogamente, alguns sugerem que a expressão 'não-identidade' é infeliz. O melhor nome para o princípio seria 'não-autoexplicação [non-selfexplanation] ${ }^{13}$, porque o princípio reza que, se determinado ente $\mathrm{x}$ possui a propriedade $\mathrm{F}$, a posse de $\mathrm{F}$ não pode ser explicada com apelo ao próprio $\mathrm{x}$, sendo preciso um outro ente, ou seja, $\mathrm{y}$, em função do qual x possui $\mathrm{F}$; em suma, a posse de uma propriedade não se explica por referência ao próprio indivíduo que a possui.

10 Em inglês, self-exemplification. Cf. Moravcsik (1976).

11 O próprio Vlastos (1969, pp. 300, n. 36) reconhece a utilidade de semelhante distinção: "I so labelled this assumption in 1954 under Taylor's influence, who had identified it uncritically with the closely related assumption, that a character can be predicated of itself, which generated the Russellian paradox. Since I did not impute just this assumption to Plato - I was not maintaining that what was predicated of F-ness was F-ness itself instead of F - I should have made it clear then [...] that 'Self-Predication', if used at all, could only be used with a certain licence. As Sellars had pointed out (1955, pp. 414), the assumption which is being made here "would be formulated more correctly as 'The adjective corresponding to the name of any Form can correctly be predicated of that Form'". Some such label as 'Homocharacterization' would have been more exact, and I have tried at times to switch to this in lectures and seminars. But 'Self-Predication' is now firmly entrenched in the literature, and I see no harm in its continuing use subject to the above proviso".

13 Tudo que se poderia fazer é questionar a extensão deste princípio, isto é, que tipo de multiplicidade é capaz de gerar uma Ideia; de fato, a bem pensar, isso é exatamente o que se vê em Prm. 130b-e, quando a personagem-título interroga se existem Ideias correspondentes a multiplicidades ignóbeis (lama, cabelo, poeira). 
Tal como no caso da autopredicação, mesmo concordando com as ressalvas, preferimos nos ater à terminologia consagrada: neste caso, o princípio da não-identidade.

\section{Proposta de solução para a aporia do Terceiro Homem}

Como vimos, o argumento do Terceiro Homem redunda na temível multiplicação das Ideias. Este argumento é composto por três princípios, "um de muitos", autopredicação e não-identidade, e é do seu encadeamento que provém a série infinita. Sendo assim, quem pretenda afirmar que este argumento não constitui uma objeção definitiva à teoria das Ideias não pode aceitar que esses três princípios integrem a filosofia de Platão; caso contrário, a própria teoria das Ideias estaria sujeita à objeção do Terceiro Homem, e seguir-se-iam as consequências acima analisadas.

Por outro lado, negar ou modificar pelo menos um dos três princípios bastaria para impedir a multiplicação das Ideias. Mas por a questão dessa forma pode ser enganador. Não se trata simplesmente de escolher qual das premissas será objeto de intervenção, como se estas fossem peças de um tabuleiro, que, sendo movidas deste ou daquele modo, pudessem conduzir à vitória. Trata-se, pelo contrário, de avaliar se a filosofia de Platão fornece elementos que permitam evitar a objeção do Terceiro Homem; assim, o que está em jogo não são apenas as premissas de um argumento isolado, mas sim princípios gerais da teoria das Ideias.

Sendo assim, se, à primeira vista, o caminho para a solução da aporia do Terceiro Homem parece simples, a tarefa revela-se, ao cabo, muito mais complexa: há de se considerar, a cada passo, as consequências que a intervenção num ou noutro princípio podem acarretar para a filosofia de Platão, considerada no seu todo. Feitas essas considerações, iniciemos a análise das possibilidades disponíveis ao intérprete.

O princípio do "um de muitos" reza que a cada multiplicidade de indivíduos que possui certa propriedade deve corresponder uma unidade responsável (causalmente) por essa propriedade. Concretamente, se os indivíduos a, b e c são grandes, deve haver também uma Ideia de Grandeza. A verdade é que este princípio está no âmago da hipótese das Ideias e não pode ser questionado; fazê-lo implicaria destruir a intuição mais fundamental do platonismo ${ }^{14}$. Sendo assim, resta apreciar se a autopredicação e a não-identidade são autênticos princípios da teoria das Ideias. Vejamos, em primeiro lugar, a autopredicação. 
Toda a problemática da autopredicação pode ser reduzida a duas perguntas: $(\alpha)$ a teoria das Ideias implica a autopredicação? ( $\beta)$ Se sim, em que medida? A segunda questão é claramente dependente da primeira; voltemos, portanto, nossa atenção para esta.

O modo mais intuitivo de investigar se a autopredicação integra, ou não, a teoria das Ideias seria examinar as passagens dos diálogos que contêm, prima facie, juízos autopredicativos ${ }^{15}$. De fato, existem trabalhos exclusivamente devotados a determinar quais trechos do corpus platonicum podem ser contados como testemunhos explícitos da autopredicação ${ }^{16}$. Mas seria este o único método para se determinar se a autopredicação é um genuíno princípio da teoria das Ideias? Parece-nos que não. Desde que o intérprete parta de uma Ideia bem atestada pelos diálogos, nada impede que ele investigue se esta Ideia é ou não sujeita à autopredicação, independentemente do testemunho dos diálogos. Por exemplo, não se encontra na obra de Platão a categórica afirmação "a Ideia de Ser é", ou "a Ideia de Repouso está em repouso", mas é perfeitamente lícito questionar se tais autopredicações seriam válidas. De acordo com este método, julgamos ser possível responder à primeira das questões acima mencionada, nomeadamente, $(\alpha)$ se a teoria das Ideias implica a autopredicação.

Defendemos, pois, um âmbito de Ideias a respeito das quais a autopredicação não somente não é problemática, mas é verdadeiramente obrigatória. Assim, são exemplos de autênticos juízos autopredicativos "a Ideia de Ser é", "a Ideia de Outro é outra (que as demais Ideias)", "o Mesmo é o mesmo (que si mesmo)", "o Repouso está em repouso", "a Unidade é uma”. Estes juízos dizem respeito a propriedades sem as quais a própria concepção das Ideias estaria ameaçada; dito de outro modo, se da Ideia de Ser não se puder dizer que ela é, se dela não se puder "predicar" o "é", a própria existência da Ideia estaria em xeque. Analogamente, é impossível não reconhecer a validade da autopredicação referente à Ideia de Repouso: negá-lo implicaria que a Ideia de Repouso esteja sujeita ao movimento. E o mesmo tipo de argumentação pode ser desenvolvido também a propósito das Ideias de Outro, de Mesmo e de Unidade ${ }^{17}$.

Cremos, deste modo, poder afirmar que a autopredicação é um genuíno princípio da teoria das Ideias, em que pese o caráter incontestável de alguns casos de autopredicação. Mas teria este princípio validade irrestrita, isto é,

16 Note-se que foi com base nestes juízos autopredicativos que procuramos refutar posições extremadas como as defendidas por Harold Cherniss (1957) e Reginald Allen (1960), os quais pretendem excluir tout court a autopredicação da obra de Platão.

17 Este não é um exemplo qualquer. Como sabemos, na "primeira versão" do chamado argumento do Terceiro Homem, a Ideia em questão é justamente a Ideia de Grandeza. Vimos também que, para que o argumento "funcione", isto é, para que seja gerada a série infinita de Ideias, é indispensável que a autopredicação valha para a Ideia de Grandeza, predicação que é, porém, particularmente absurda. A personagem de Sócrates no "Parmênides", contudo, não foi capaz de detectar o problema em tela. 
toda e qualquer Ideia admitida por Platão estaria sujeita à autopredicação? A resposta só pode ser negativa.

Existem Ideias às quais certamente não convém a autopredicação, por exemplo, as Ideias de Movimento, Justiça, Piedade, Coragem, Grandeza, Pequenez, etc. Afirmar que a Ideia de Movimento se move, isto é, que ela, de algum modo, se altere, implica contrariar uma característica fundamental das Ideias, a sua inalterabilidade. E como poderia a Ideia de coragem ser corajosa? Esta parece ser uma afirmação simplesmente vazia de significado, e a mesma dificuldade semântica se repete com a autopredicação da Justiça, Piedade, etc. No caso da Grandeza, a autopredicação é particularmente grosseira: a natureza de toda e qualquer Ideia impede que dela se predique o "grande", uma vez que as Ideias são, por definição, incorpóreas ou imateriais, e o conceito de grande contém, analiticamente, a noção de corporeidade ou materialidade ${ }^{18}$.

Em suma, existe um grupo de Ideias que decididamente está fora do âmbito da autopredicação. Alguns comentadores, porém, defendem que a autopredicação é um princípio que se aplica a todas as Ideias. É indispensável, neste caso, fornecer alguma explicação suplementar para lidar com os referidos paradoxos associados a esta posição. As soluções aqui variam muito, mas uma delas é recorrente e merece ser lembrada. Ela consiste em pretender retirar, de algum modo, a força propriamente predicativa das autopredicações, isto é, defender que a predicação envolvida numa autopredicação não seja uma predicação ordinária ${ }^{19}$. De nossa parte acreditamos ser muito mais econômico e, sobretudo, muito mais claro não aventar qualquer nova espécie de predicação; em vez de pretender remediar deste modo os casos problemáticos de autopredicação, preferimos simplesmente reduzir o seu âmbito: a autopredicação vale para determinadas Ideias, e não vale para outras. Assim, embora a autopredicação não seja irrestrita, nos casos em que a admitimos, não precisamos lançar mão de qualquer subterfúgio: o que se tem é a predicação, no sentido mais inteligível e ordinário do termo.

Defendemos, portanto, que a autopredicação seja um princípio da teoria das Ideias, cuja amplitude, porém, é restrita. Podemos chamá-lo, assim, de princípio da autopredicação fraco, uma vez que só se aplica a certas Ideias.

Constance Meinwald (1991), por exemplo, propõe a predicação pros heauto (em contraposição à predicação pros ta alla); de modo semelhante, Francesco Fronterotta (2001) lança mão da obscura noção de predicação formal (em oposição a uma suposta predicação concreta). Para uma crítica mais detalhada da posição desses autores, cf. CECÍLIO (2016).

Uma vez que nosso objetivo se limita a investigar se existem Ideias sujeitas à autopredicação, e não quais sejam exatamente estas Ideias, acreditamo-nos dispensados da tarefa de avaliar os trechos do corpus que poderiam fornecer um testemunho explícito da autopredicação. Mesmo que seja possível, por princípio, determinar pelo menos algumas das referências textuais da autopredicação, fazê-lo in concreto arriscaria lançar este trabalho num emaranhado de problemas, tais como o contexto específico de cada passagem, o que poderia acabar por nos desviar de nossa meta geral. 
É preciso prestar ainda um último esclarecimento. Alguém poderia exigir de nós mais clareza quanto aos casos de autopredicação que admitimos, ou seja, uma resposta mais precisa à questão $(\beta)$ acima mencionada: afinal, quais Ideias, exatamente, são sujeitas à autopredicação, e quais não o são?

A verdade é que o nosso trabalho não visa a fornecer uma lista completa das Ideias às quais a autopredicação se aplica, mas sim apresentar uma solução para a aporia do Terceiro Homem. E para satisfazer semelhante objetivo, importa saber se existem Ideias sujeitas à autopredicação, mas é dispensável conhecer o elenco completo dessas Ideias. De fato, se a autopredicação estivesse completamente excluída da filosofia de Platão, cairia então por terra a aporia do Terceiro Homem porque, como sabemos, a autopredicação é uma das premissas essenciais para o funcionamento do argumento. Mas, admitindo-se pelo menos um caso de autopredicação, a dificuldade do regressus persiste, ao menos no que diz respeito à Ideia em questão.

Sendo assim, escusamo-nos da tarefa de determinar exaustivamente a que Ideias a autopredicação se aplica, ainda que se trate de Ideias muito bem documentadas, como é o caso da Beleza ou do Bem. Os exemplos que aduzimos são suficientemente seguros para afirmarmos que a autopredicação vale para certas Ideias, mas não para outras, e isto é quanto basta para que possamos propor, em geral, uma solução para o Terceiro Homem² ${ }^{20}$.

Voltemos agora nossa atenção ao princípio de não-identidade. Sugerimos acima a seguinte formulação: "Se x é F, x não coincide com $\Phi$, a Forma em virtude da qual x é F". Este princípio funciona normalmente quando os substitutos da variável x são indivíduos sensíveis: se estas árvores são unas, elas não coincidem com a Unidade, a Ideia em virtude da qual elas são unas. Mas sabemos que a própria Ideia de Unidade é una, o que implicaria a existência duma nova Ideia de Unidade: "se a Unidade é una, a Unidade não coincide com Unidade ${ }_{1}$, a Forma em virtude da qual a Unidade é uma".

Está claro que o regresso infinito das Ideias é fruto da conjunção da autopredicação com o princípio de não-identidade. O princípio fraco da autopredicação, que há pouco propusemos, não é, portanto, suficiente para livrar a teoria das Ideias desta dificuldade, porque, de acordo com ele, pelo menos algumas Ideias estão sujeitas à autopredicação, de modo que, ao menos nestes casos, recair-se-ia no regressus.

20 Fronterotta (2008, pp. 431, n. 231) comenta assim a passagem: "In effetti, è precisamente in virtù de della partecipazione al genere del diverso [...] che gli altri generi acquisiscono la propria rispettiva diversità, che dunque non possiedono di per sé: la diversità è insomma un elemento o una proprietà che si aggiunge a ogni genere e che non appartiene immediatamente alla natura propria di ciascuno di essi [...] in modo che, secondo Platone, il genere 'uomo' e 'albero', per esempio, risultano esclusivamente 'uomo' e 'albero' e, per acquisire ogni altra proprietà, compresa l'identità con sé e la diversità dall'altro da sé, devono per necessità stabilire dei rapporti di communicazione con il genero dell'identico e con il genere del diverso [...]". 
Para resolver definitivamente a aporia é preciso, portanto, impedir que o princípio da não-identidade valha também nos casos em que se admite a autopredicação. Neste sentido, basta que se restrinja o escopo da variável x: "Se x é F, x não coincide com $\Phi$, a Forma em virtude da qual x é F, para todo $\mathbf{x}$ indivíduo sensível". Deste modo, ficaria vedado a uma Ideia F-dade, ainda que ela satisfaça a condição de ser caracterizada por F (antecedente do condicional), constar como o substituto da variável x. Poderíamos chamar o princípio assim modificado de princípio fraco de não-identidade, uma vez que sua validade é restrita.

Mas a questão ainda não está plenamente resolvida. O princípio fraco de nãoidentidade simplesmente afasta de seu horizonte, por meio de uma cláusula especial, a autopredicação das Ideias; mas o fato de F-dade possuir $\mathrm{F}$ é algo que requer uma explicação positiva.

Importa assegurar que a autopredicação de uma Ideia não se explique com recurso a uma nova Ideia, a qual, sendo também ela sujeita à autopredicação, requisitaria outra Ideia, e assim ad infinitum. A solução que nos parece mais plausível seria supor que F-dade possui a propriedade F por causa de si mesma; destarte, existe, sim, uma Ideia em virtude da qual F-dade é F, mas essa Ideia é a própria F-dade.

De acordo com esta tese, se várias coisas são unas, tais como Sócrates e esta árvore, elas o são em virtude da Ideia de Unidade, ao passo que a Ideia de Unidade é una por causa de si mesma. Em resumo, (quando há) autopredicação de uma Ideia platônica, ela não se explica com recurso a uma nova Ideia, o que engendraria uma série infinita de Ideias, mas sim pela própria Ideia: F-dade possui a propriedade $\mathrm{F}$ em virtude de si mesma.

O princípio fraco de não-identidade é, portanto, apenas parte da solução; é preciso lançar mão também de um novo mecanismo para resolver definitivamente a aporia, o qual poderíamos alcunhar, por falta de melhor termo, de princípio de autodeterminação: "Se F-dade é F, a Forma em virtude da qual F-dade é F é a própria F-dade". É evidente que tal princípio coaduna-se perfeitamente com o restante de nossa interpretação: uma vez que admitimos alguns casos de autopredicação, o princípio que acabamos de propor afasta a objeção do Terceiro Homem que seria possível levantar contra estas Ideias.

Defendemos acima que a teoria das Ideias esteja comprometida com o princípio fraco de autopredicação, e o fizemos com base na força dos exemplos que aduzimos, tanto nos casos em que a autopredicação é obrigatória quanto naqueles em que ela é impossível. Mas não podemos fazer o mesmo no que diz respeito ao princípio de autodeterminação. Não é nada óbvio que Platão tivesse de aceitar que a posse de $\mathrm{F}$ por parte de F-dade se explique por autorreferência; afinal de contas, a posse de $\mathrm{F}$ por parte das coisas sensíveis se explica sempre por referência a um indivíduo, F-dade, que é nitidamente distinto das coisas sensíveis de que se partiu. 
Neste caso, se não conseguirmos apresentar alguma passagem dos diálogos em apoio à nossa tese, não nos será lícito supor que o princípio de autodeterminação integre a filosofia de Platão, a despeito de ser esta, em nosso parecer, a solução mais promissora para a aporia do Terceiro Homem. Julgamos, todavia, ser possível encontrar o desejado apoio numa célebre passagem do "Sofista". Antes de analisá-la, cabe uma observação.

Estamos à procura dum trecho que ateste que a posse de $\mathrm{F}$ por parte de Fdade - a autopredicação das Ideias - seja explicada por autorreferência, e não por recurso a outra Ideia. Seria ingenuidade pretender aduzir um trecho dos diálogos em que Platão o asseverasse de modo claro, explícito e incontestável: se esta referência existisse, ela certamente já teria sido encontrada por algum dos inúmeros e competentes estudiosos que se dedicaram à questão. O texto que analisaremos serve, contudo, como um forte indício de que a teoria das Ideias seja compatível com o princípio de identidade, e talvez não se possa exigir nada além disso.

Trata-se duma seção do "Sofista" que constitui, sem dúvida, um dos trechos mais significativos da chamada doutrina das Ideias:

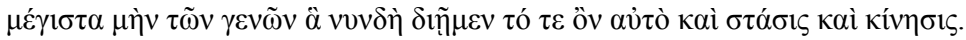

$\pi \mathrm{o} \lambda \hat{v} \gamma \varepsilon .[\ldots]$

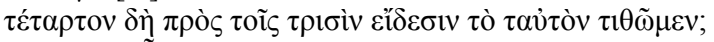

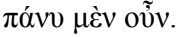

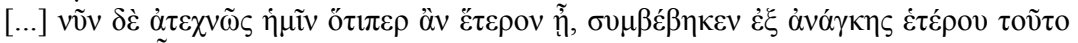

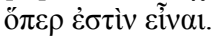

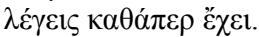

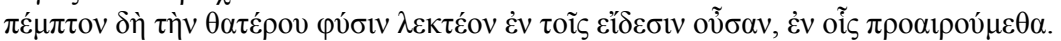
vaí.

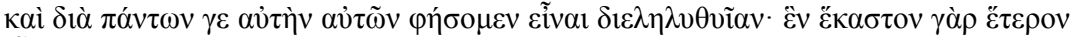

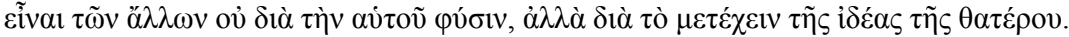

- Ora, os mais importantes desses gêneros são precisamente aqueles que acabamos de examinar, o próprio ser, o repouso e o movimento.

- De longe, os maiores. [...]

- Deveremos, pois, às três formas precedentes, adicionar "o mesmo" como quarta forma?

- Perfeitamente.

- [...] Ora, já vimos perfeitamente que tudo que é outro só o é por causa de sua relação necessária a outra coisa.

- Certamente.

- É necessário, pois, considerar a natureza do "outro" como uma quinta forma, entre as que já estabelecemos.

- Sim.

- Diremos, também, que ela se estende através de todas as demais. Cada uma delas, com efeito, é outra além do resto, não em virtude de sua própria natureza, mas pelo fato de que ela participa da forma do "outro". (Sph. 254d-255e).

A passagem informa inequivocamente que cada Ideia é diferente das de- 
mais Ideias "não em virtude de sua própria natureza, mas pelo fato de que ela participa da forma de "outro""; isto é, o fato inegável de que cada Ideia é diferente de todas as outras Ideias explica-se pela relação com uma Ideia, nomeadamente, a Ideia de Outro21.

Semelhante tese não nos deve surpreender: de acordo com a filosofia de Platão, é perfeitamente trivial explicar o fato de certo indivíduo possuir uma propriedade por referência a uma Ideia; o que há aqui de excepcional é apenas o fato de que os sujeitos a que convém certa propriedade são as próprias Ideias e não, como sói ocorrer, meros indivíduos sensíveis. De todo modo, é perfeitamente claro que Platão pretende fornecer uma justificativa para a distinção recíproca de todas as Ideias: cada Ideia se distingue das demais em virtude de sua relação com a Ideia de Outro.

O mesmo tipo de procedimento está presente em toda a passagem da

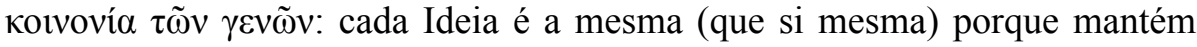
certo tipo de relação com a Ideia de Mesmo; assim também para as Ideias de Repouso e de Ser22. Mas voltemos nossa atenção ao caso da Ideia de Outro.

Embora a passagem não o afirme explicitamente, é inegável que a Ideia de Outro difere das demais Ideias; a alteridade é necessariamente uma relação recíproca: se uma Ideia qualquer se distingue da Ideia de Outro é porque a Ideia de Outro também dela se distingue. Isso quer dizer que "a Ideia de Outro

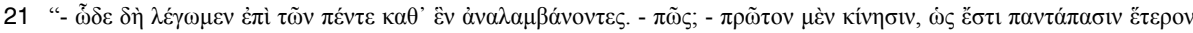

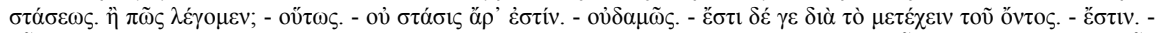

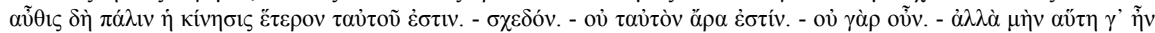

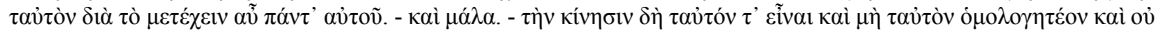

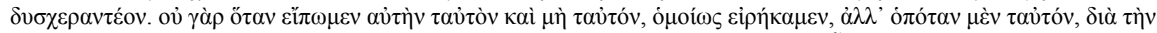

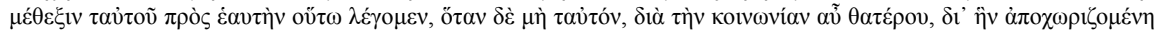

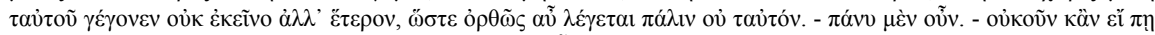

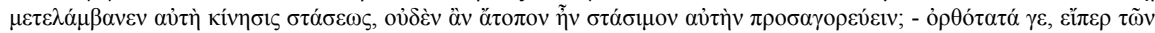

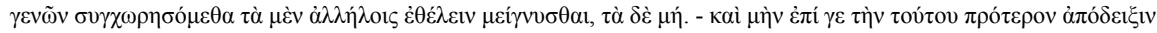

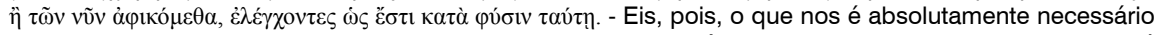
dizer a respeito dessas cinco formas tomadas uma a uma. - O quê? - Em primeiro lugar, o movimento: ele é absolutamente outro que não o repouso. Não é o que dizemos? - É. - Logo, ele não é repouso. - De maneira alguma. - Entretanto, ele "é" pelo fato de participar do ser. - É. - E mais: o movimento é outro que não o "mesmo". - Certamente não. - Entretanto, vimos que ele é o mesmo, pois como conviemos tudo participava do mesmo. - Certamente. - Então o movimento é o mesmo, e não o mesmo: é necessário convir nesse ponto sem nos afligirmos, pois, quando dizemos o mesmo e não o mesmo, não nos referimos às mesmas relações. Quando afirmamos que ele é o mesmo é porque, em si mesmo, ele participa do mesmo, e quando dizemos que ele não é o mesmo, é em consequência de sua comunidade com o "outro", comunidade esta que o separa do "mesmo" e o torna não-mesmo, e sim outro; de sorte, neste caso, temos o direito de chamá-lo "não o mesmo". - Perfeitamente. - Se, pois, de alguma maneira, o próprio movimento participa do repouso, haveria algo de estranho em chamá-lo de estacionário? - Seria, ao contrário, perfeitamente correto, se devemos convir que, entre os gêneros, uns se prestam, à associação mútua, outros não. - Ora, essa é justamente a demonstração à qual havíamos chegado antes de atingirmos esta, e havíamos provado que é precisamente essa a sua natureza." Sph. 255e-256c.

22 O mesmo tipo de argumentação pode ser desenvolvido com relação também ao gênero do Ser, do Repouso e do Mesmo. Certamente "o Ser é", "o Repouso está em repouso" e "o Mesmo é o mesmo (que si mesmo)"; todas estas autopredicações devem ser explicadas do mesmo modo como se explica a posse destes predicados por parte de qualquer outra Ideia, isto é, por referência às Ideias de Ser, Repouso e Mesmo. 
é outra (que as demais Ideias)", ou seja, a Ideia de Outro é autopredicativa.

Ora, se cada Ideia se distingue das demais em virtude de sua relação com a Ideia de Outro, por coerência tal explicação deveria valer também para a Ideia de Outro: a Ideia de Outro difere de qualquer (outra) Ideia por sua relação com a Ideia de Outro, isto é, por uma relação que a Ideia de Outro mantém consigo mesma23. Em termos gerais, isso significa que a Forma em virtude da qual F-dade é $\mathrm{F}$ é a própria F-dade, ratificando assim aquilo que chamamos de princípio de autodeterminação. Atingiríamos, assim, a nossa meta: a кoıvoví $\alpha \tau \tilde{\omega} v$ $\gamma \varepsilon v \tilde{\omega} v$ forneceria o desejado fundamento textual a partir do qual poderíamos afirmar que a autopredicação seria explicada por autorreferência, o que, como vimos, constitui a escapatória definitiva para a aporia do regresso infinito. É preciso, porém, nos determos por um momento.

Se levarmos às últimas consequências a doutrina presente no trecho citado, isso nos comprometeria com a duvidosa, para dizer o mínimo, doutrina da autoparticipação das Ideias.

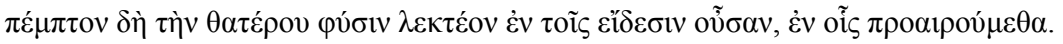
vaí.

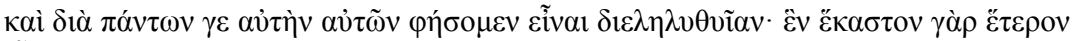

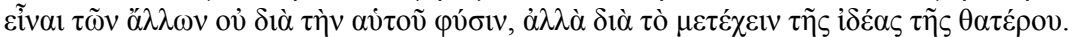
- É necessário, pois, considerar a natureza do "outro" como uma quinta forma, entre as que já estabelecemos.

- Sim.

- Diremos, também, que ela se estende através de todas as demais. Cada uma delas, com efeito, é outra além do resto, não em virtude de sua própria natureza, mas pelo fato de que ela participa da forma do "outro". (Sph. 255d-e).

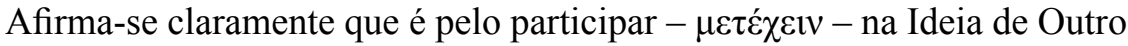

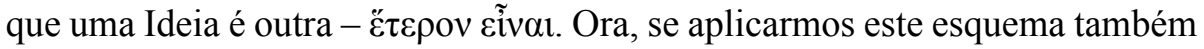
à Ideia de Outro, segue-se que a Ideia de Outro é outra porque participa de si mesma. Mas não se deve forçar demasiadamente o texto.

Bem ao contrário, devemos reconhecer que a passagem verossimilmente não tem em vista a Ideia de Outro, mas sim as demais Ideias, a respeito das quais se afirma que elas são outras não por suas próprias naturezas, mas pela participação na Ideia de Outro; a Ideia de Outro, inversamente, teria de ser

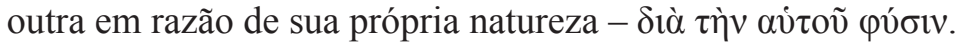

Em suma, não pretendemos que esta seção do "Sofista" contenha explicitamente o que chamamos de princípio da autodeterminação, a doutrina segun- 
do a qual F-dade possui $\mathrm{F}$ em virtude de si mesma, e não virtude de uma outra qualquer Ideia. Sustentamos apenas que tal doutrina não é incompatível com esta passagem, ou melhor, que dela se segue por coerência: se a posse de uma propriedade $\mathrm{F}$ por parte de um sujeito é ordinariamente justificada com base numa relação do sujeito com F-dade, então quando o sujeito em questão é a própria Ideia F-dade, a explicação deve ser idêntica, a saber, F-dade possui $\mathrm{F}$ em razão de algum tipo de relação com F-dade, isto é, consigo mesma24.

O resultado com que nos defrontamos é este. A solução adequada para a aporia do Terceiro Homem envolve o princípio de autodeterminação, segundo o qual certas Ideias possuem as propriedades a elas associadas (autopredicação) em virtude de si mesmas. Hesitamos em afirmar categoricamente que o "Sofista" contenha, ao menos de modo totalmente explícito, este princípio; contudo, parece-nos ser possível inferir o referido princípio do "Sofista" de modo razoavelmente simples. Por um lado, a kovvovía $\tau \tilde{\omega} v \gamma \varepsilon v \tilde{\omega} v$ implica que a posse de uma propriedade F se explica por referência a F-dade; por outro lado,

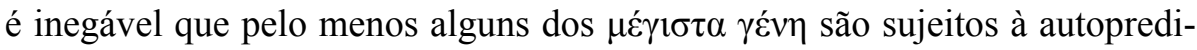
cação: como duvidar de que "o Ser é"? A conjunção dessas duas teses permite concluir que a autopredicação das Ideias se explica por autorreferência, afastando-se, assim, definitivamente a ameaça do regressus infinitum das Ideias.

\section{Conclusão}

No início deste trabalho, manifestamos nossa opinião de que, a despeito das autocríticas do "Parmênides", Platão jamais chegou a abandonar a teoria das Ideias; há, de fato, fortes motivos para crê-lo, dentre os quais a provável posterioridade do "Sofista" e, sobretudo, do "Timeu" com relação ao "Parmênides" (sendo estes dois diálogos que inequivocamente sustentam a existência das Ideias), bem como a completa ausência de qualquer testemunho antigo que sequer sugira semelhante recuo por parte de Platão.

Platão se mostra perfeitamente cônscio da indispensabilidade das Ideias, a ponto de pôr na boca de Parmênides, ao final da série de objeções que a personagem opusera ao jovem Sócrates, o seguinte juízo:

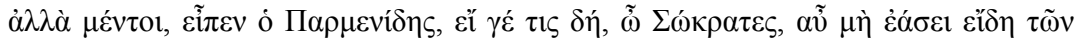

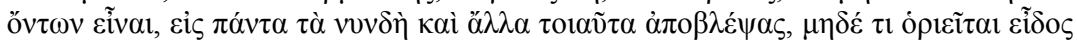

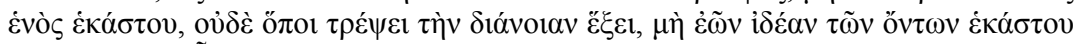

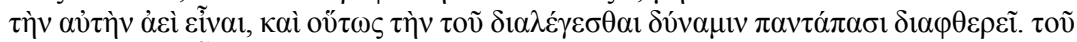

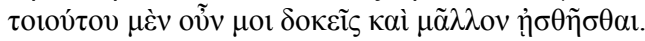

$\dot{\alpha} \lambda \eta \theta \tilde{\eta} \lambda \varepsilon ́ \gamma \varepsilon 1 \zeta, \varphi \alpha ́ v \alpha 1$.

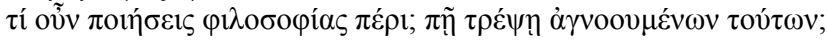




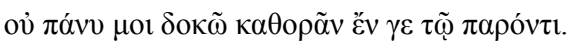

Entretanto, Sócrates, disse Parmênides, se alguém, por outro lado, ao atentar para todas as coisas mencionadas há pouco e para outras desse tipo, não admitir que haja formas dos seres e não definir uma forma de cada coisa uma, nem sequer terá para onde voltar o pensamento, uma vez que não admitirá haver uma ideia sempre a mesma de cada um dos seres, e assim arruinará absolutamente o poder do dialogar. Pareces-me, seguramente, estar ciente, e muito, de tal coisa.

Dizes a verdade, disse ele.

Que farás então da filosofia? Para onde te voltarás, sendo estas coisas desconhecidas?

Acho que não vejo bem, pelo menos no presente. (Prm. 135b-c).

Mas o diálogo não termina com esta nota melancólica; bem ao contrário, Parmênides indica ser a inexperiência de Sócrates a causa do embaraço em que ele se encontra, e recomenda-lhe que se exercite mais:

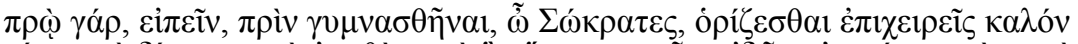

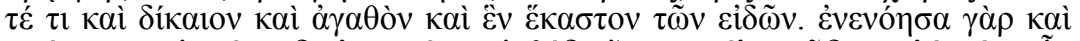

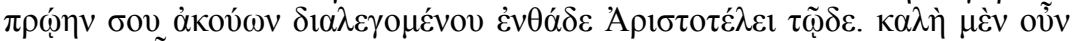

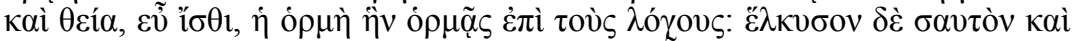

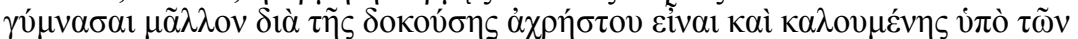

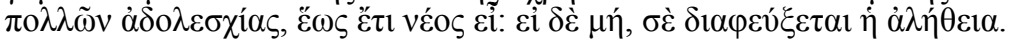

É que, Sócrates, disse ele, tentas cedo demais antes de te exercitares $[\gamma v \mu v \alpha \sigma \theta \eta \tilde{v} \alpha 1]$, separar um belo e um justo e um bem e cada coisa uma dentre as formas. Pois dei-me conta disso bem recentemente, ouvindo-te aqui dialogar com Aristóteles aqui presente. Pois fica sabendo que, realmente, é belo e divino esse ardor que lanças sobre os argumentos. Mas esforça-te e exercita-te mais, enquanto ainda és jovem, por meio disso que, pela maioria, é tido como inútil e chamado de tagarelice. Se não, a verdade te escapará. (Prm. 135c-d) ${ }^{25}$.

O que segue é a famosa $\gamma u \mu v \alpha \sigma i ́ \alpha$, conduzida por Parmênides e levada a cabo em companhia dum jovem Aristóteles, $\gamma v \mu v \alpha \sigma i ́ \alpha$ que deveria servir como exemplo do tipo de exercício que o Eleata há pouco sugerira a Sócrates. Foge completamente ao escopo deste trabalho determinar o seu exato significado, mas é certo que ele deveria servir, no mínimo, para robustecer a capacidade dialógica de Sócrates, habilitando-o a melhor defender a doutrina das Ideias das diversas objeções que se lhe podem opor.

Note-se que a $\gamma v \mu v \alpha \sigma i ́ \alpha$ constitui a maior série contínua de argumentos de todo o corpus platonicum. $\mathrm{O}$ fato de Parmênides aconselhar Sócrates a praticar semelhante exercício faria pouco sentido, se as objeções que ele há pouco levantara contra a hipótese das Ideias devessem contar como entraves intrans- 
poníveis; fossem as aporias insolúveis, o longo, e por que não dizê-lo, fatigante exercício converter-se-ia num jogo conceitual vazio ou mesmo numa acre ironia do autor do diálogo.

Por outro lado, sabemos que as objeções levantadas à teoria das Ideias não encontram nenhuma resposta explícita nem no "Parmênides", nem em qualquer outro diálogo; e o mesmo vale, naturalmente, para o nosso objeto de estudo, a objeção do Terceiro Homem. Mas significaria isto, necessariamente, que a teoria das Ideias seja incapaz de fornecer-lhe qualquer resposta, devendo, por conseguinte, capitular? Parece-nos que não. É verdade que Platão não redigiu a refutação para o Terceiro Homem, mas cremos que esta pode ser individuada a partir de elementos de sua filosofia. Para mostrá-lo, fez-se necessário o exame detido deste argumento e de sua estrutura lógica.

Procuramos esclarecer, em primeiro lugar, que o Terceiro Homem não encerra, como pretendeu Vlastos, nenhum tipo de contradição stricto sensu, mas sim uma imponente dificuldade, a série infinita das Ideias, que se mostra ainda mais temível quando considerada sob o prisma da função causal da hipótese das Ideias. Mas esta só constitui uma ameaça efetiva à teoria das Ideias se se admitir que os princípios incluídos neste argumento em particular possuam validade universal na filosofia de Platão, o que não nos parece ser o caso.

Destarte, defendemos que a solução definitiva para o problema envolve a flexibilização de dois dos princípios implícitos no argumento, a não-identidade e a autopredicação.

Se, por um lado, é perfeitamente razoável supor que pelo menos algumas Ideias tenham de estar sujeitas à autopredicação, seria impensável pretender que o mesmo valha para todas elas. Mas, nos casos em que admitimos a autopredicação, a objeção do Terceiro Homem continuaria operante: a posse da propriedade $\mathrm{F}$ por parte de F-dade exigiria uma nova Ideia, F-dade1, a qual, por estar, também ela, sujeita à autopredicação, requereria outra Ideia, e assim sucessivamente. Mas tal conclusão não se impõe forçosamente.

Argumentamos que uma importante passagem do "Sofista" contém a tese de que a posse da propriedade $\mathrm{F}$ por parte de um sujeito qualquer se explica por referência à Ideia F-dade; por que semelhante explicação não deveria valer também para os casos em que a propriedade $\mathrm{F}$ é atribuída à própria $\mathrm{F}$-dade? Dessa passagem extrai-se, pois, por coerência, aquilo que chamamos de princípio de autodeterminação: se F-dade possui F, F-dade o possui em virtude de si mesma.

Assim sendo, mesmo nos casos em que se tem a autopredicação, o fato de tais Ideias possuírem as propriedades a elas associadas se explica por autorreferência, estando assim a ontologia de Platão imune à objeção do regressus.

A solução por nós delineada é dotada de duas qualidades; por um lado, 
ela se harmoniza muito bem com a doutrina das Ideias, e, por outro lado, ela é razoavelmente simples, o que faz com que seja muito verossímil que ela estivesse à disposição do filósofo.

De fato, é evidente que as Ideias de Ser e de Unidade, por exemplo, estão sujeitas à autopredicação, como também é forçoso reconhecer que a Grandeza não pode ser grande, a Pequenez pequena, etc.; e, se isso é óbvio para nós, não temos qualquer motivo para crer que não o fosse também para Platão.

O princípio da autodeterminação, essencial como ele é para a resolução do

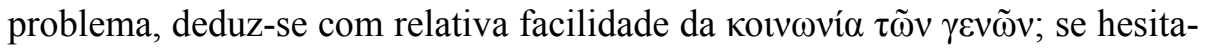
mos em afirmar categoricamente que Platão tenha sustentado este princípio, é pelo menos muito plausível que ele o tenha feito.

Em suma, se é inegável que Platão não nos legou uma resposta explícita para o Terceiro Homem, é provável que esta lhe estivesse à mão. Assim, ao menos no que concerne às dificuldades que esta aporia lhe opõe, compreendese que Platão não tenha sido forçado a abdicar do cerne de sua filosofia, a doutrina das Ideias.

\section{Referências}

ALLEN, Reginald. "Participation and Predication in Plato's Middle Dialogues". The Philosophical Review, v. 68, n. 2, 1960. pp. 147-164.

BURNET, John. "Platonis Opera”. Oxford: Clarendon Press, 1903.

CECÍLIO, G. C. A. "Considerações acerca do debate em torno do Argumento do Terceiro Homem no Parmênides de Platão". Journal of Ancient Philosophy, v. 10, 2016. pp.13-44.

um Texto Seminal”. Clássica, v. 28, n.2, 2015. pp. 171-183

CHERNISS, Harold. "The Relation of the Timaeus to Plato's Later Dialogues". The American Journal of Philology, v. 78, n. 3, 1957. pp. 225-266.

COHEN, Marc. "The Logic of the Third Man". The Philosophical Review, v. 80, n. 4, 1971. pp. 448-475.

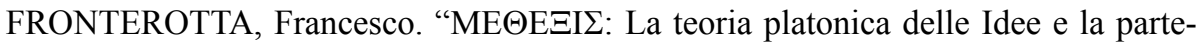
cipazione delle cose empiriche - Dai dialoghi giovanili al Parmenide". Pisa: Scuola Normale Superiore, 2001.

JAEGER, Werner. "Aristotelis Metaphysica”. Oxford: Oxford University Press, 1957. KRAUT, Richard (ed.). "The Cambridge Companion to Plato". New York: Cambridge University Press, 1993.

MALCOLM, John. "Plato on the Self-Predication of Forms: Early and Middle Dialogues". Oxford: Clarendon Press, 1991.

MEINWALD, Constance. "Plato's Parmenides". New York: Oxford University Press, 1991. 
1993. pp. 365-396.

MORAVCSIK, Julius. "Recollecting the Theory of Forms". In: Werkmeister, W. D. (ed.), 1976. pp. 1-20.

PETERSON, Sandra. "A Reasonable Self-Predication Premise for the Third Man Argument”. The Philosophical Review, v. 82, n. 4, 1973. pp. 451-470.

PLATÃO. "Diálogos II: Fédon-Sofista-Político". Tradução de João Cruz Costa e Jorge Paleikat. Rio de Janeiro: Ediouro, 19--.

BUR, 2007.

. "Parmenide". Introduzione, traduzione e note di Franco Ferrari. Milano: . "Parmênides". Tradução e notas de Maura Iglésias e Fernando Rodrigues. São Paulo: Loyola, 2003.

"Sofista". Introduzione, traduzione e note di Francesco Fronterotta. Milano: BUR, 2008.

SAYRE, Kenneth. "Plato's Late Ontology: a Riddle Resolved". Las Vegas: Parmenides Publishing, 2005.

SILVERMAN, Allan. "The Dialectic of Essence: a Study of Plato's Metaphysics". Princeton: Princeton University Press, 2002.

STRANG, Colin. "Plato and the Third Man". Proceedings of the Aristotelian Society, v. 37, 1963. pp. 147-164.

VLASTOS, Gregory. "The Third Man Argument in the Parmenides". The Philosophical Review, v. 63, n. 3, 1954. pp. 319-349.

. 'Plato's 'Third Man' Argument (Parm. 132A1-B2): Text and Logic". The Philosophical Quarterly, v. 19, n. 77, 1969. pp. 289-301.

WERKMEISTER, W. H. (Ed). "Facets of Plato's Philosophy". Assen: Van Gorcum, 1976. 
